\title{
Effect of Rearing Season on Meat and Intramuscular Fat Quality of Beni-Guil Sheep
}

\author{
Kamal Belhaj $\mathbb{D}^{1,2}$ Farid Mansouri $\mathbb{D}^{1},{ }^{1}$ Marianne Sindic, ${ }^{2}$ Marie-Laure Fauconnier, ${ }^{3}$ \\ Mohamed Boukharta, ${ }^{4}$ Hana Serghini Caid, ${ }^{1}$ and Ahmed Elamrani ${ }^{1}$ \\ ${ }^{1}$ Laboratory for Agricultural Productions Improvement, Biotechnology and Environment (LAPABE), Faculty of Sciences, \\ University Mohammed First, BP-717, 60000 Oujda, Morocco \\ ${ }^{2}$ Analysis Quality and Risk Unit, Laboratory of Food Quality and Safety (QSPA), Gembloux Agro-Bio Tech, University of Liège, \\ 5030 Gembloux, Belgium \\ ${ }^{3}$ Laboratory of General and Organic Chemistry, Gembloux Agro Bio-Tech, University of Liège, Gembloux, Belgium \\ ${ }^{4}$ Institute of Agricultural Industries, High School of Charlemagne, $4500 \mathrm{Huy}$, Belgium \\ Correspondence should be addressed to Kamal Belhaj; belhaj.kamal90@gmail.com
}

Received 1 November 2020; Revised 8 March 2021; Accepted 15 March 2021; Published 24 March 2021

Academic Editor: Alessandra Del Caro

Copyright $\odot 2021$ Kamal Belhaj et al. This is an open access article distributed under the Creative Commons Attribution License, which permits unrestricted use, distribution, and reproduction in any medium, provided the original work is properly cited.

Twenty Beni-Guil-PGI female lambs were used to study the effects of rearing season on meat quality characteristics, fatty acids profile, and lipid content. The animals were reared according to the pastoral-transhumant system in the eastern region of Morocco. The treatments consisted of 10 female lambs reared in summer-autumn (SA) and slaughtered at winter season and 10 female lambs reared in winter-spring (WS) and slaughtered at spring season. After the slaughter, the longissimus lumborum was collected for each animal for meat quality analysis. Compared to lambs reared in SA, the meat from the WS group showed higher $(p<0.01) \mathrm{pH}$, chroma, and lightness values ( 5.79 vs. 5.72, 23.97 vs. 18.46, and 47.03 vs. 41.04 , respectively). On the other hand, the meat from WS presented higher $(p<0.05)$ intramuscular fat content (5.14 \% vs. 3.82\%, respectively). However, the intramuscular fat of the lambs reared in SA was characterized by greater $(p<0.01)$ PUFA percentage $(16.82 \%$ vs. $12.40 \%$, respectively), thrombogenic $(p<0.001)$ and atherogenic index $(p<0.001)$, and PUFA/SFA ratio $(p<0.01 ; 0.42$ vs. 0.25 , respectively). Nevertheless, those reared in WS season have a higher $(p<0.001)$ PUFA $n-3(2.58 \%$ vs. $1.14 \%$, respectively) content, and therefore favorable $(p<0.001) n-6 / n-3$ ratio (3.78 vs. 12.98 , respectively).

\section{Introduction}

In the last decade, with the increasing emphasis on organic food and sustainable agriculture, the use and exploitation of local breeds have received particular attention. In Morocco, a semiextensive breeding system, mainly of native breed or its crosses, is widely practiced to produce a traditional lamb slaughtered around the age of 6-8 months. Local breeds are known to be less productive than the nonnative and/or more selected breeds but are known by their adaptability, even in marginal arid lands, to climatic conditions and their high resistance to local parasites and they produce high meat quality. This is the case of the Beni-Guil IGP breed from the eastern region of Morocco. Their meat characteristics imply its potential use in an ecosustainable or organic selection system to produce a specific meat brand characteristic of the local territory. For ewes, the most frequent systems are semiextensive systems using pastures with the practice of pastoralism. Lambs weaning occurs at the age of 3 months. Generally, breeders implement a finishing stage to lambs (fattening) after weaning to increase their live weight and to improve the commercial quality of carcasses (aesthetic or service quality) according to market demand or to prepare lambs for predetermined times of the year (Aïd of sacrifice).

Red meat is considered a significant source of fat, especially saturated fatty acids (SFA). These fatty acids (FAs) are involved and associated with diseases such as coronary heart disease $[1,2]$. However, recent studies have reported 
the gap between scientific literature and commonly accepted dietary recommendations $[3,4]$. Therefore, special attention is accorded to the profile of fatty acids and their separation into SFA, monounsaturated fatty acids (MUFA), and polyunsaturated fatty acids (PUFA), particularly, PUFA $n-3$ in favor of PUFA $n-6$ [5]. Consumers tend to prefer grazed lamb meat, considering that this lamb meat is much healthier, tastier, and more natural than meat from intensive production systems. According to the natural reproduction cycle, lambs are generally born in winter and are kept in a sheepfold and breastfed by their mothers only at night until spring, because the climatic conditions are not favorable for newborn lambs to be outdoors. The availability of pasture changes according to the season. There are two major peaks in sheep feeding change which are winter (December-January) and spring (March-April). Therefore, we hypothesized that the season affects the meat quality characteristics. The aim of this study is to evaluate the influence of the rearing season (summer-autumn and winter-spring) on meat quality of Beni-Guil sheep breed.

\section{Materials and Methods}

2.1. Animal Material. The experiment consisted of two treatments: ten female lambs born in summer and reared during the summer-autumn season (SA) and slaughtered in winter and ten female lambs born in winter, reared during the winter-spring season (WS), and slaughtered in spring. The choice of female lambs was made randomly from the same breeders in the same region in the two seasons (rural commune of Ain-Beni-Mathar). The female lambs were 6 months old, weaned at the age of 3 months, of the $\mathrm{L}$ category specific to sheep under 12 months of age according to the European Commission regulation no. 823/98. The slaughtered animals weighed $35.50 \pm 1.94 \mathrm{~kg}$ for SA lambs and $35.96 \pm 2.13 \mathrm{~kg}$ for WS lambs. The average fattening state corresponds to a score of 4 according to the fatness community scale (1: very low-5: very high) for the classification of sheep carcasses EUROP and to the conformation of $\mathrm{R}$ class according to the conformation scale EUROP (P: poor-E: excellent) $[6,7]$.

The lambs were reared according to the pastoral farming system used in the eastern region of Morocco. It is a system based on grazing throughout the year (8-12 months/year depending on rainfall availability) with certain supplementation. In this region, animals moved south in winter and north in summer within the same area to graze on the alfa (Stipa tenacissima) and wormwood (Artemisia herbaalba) steppes. In this region, there is a wide variation in food supply depending on the rearing season from winter to spring. In winter, the soils are poor in plants; we find a few woody shrubs such as alfa and wormwood. On the other hand, in the spring there is a great plant diversity with the presence of plant species: wormwood (Artemisia herbaalba), alfa grass (Stipa tenacissima), sparta grass (Lygeum spartum), Atriplex (Atriplex halimus), ray-grass (Lolium perenne L.), laser white (Laserpitium latifolium), and sweet broom (Arthrophytum scoparium), along with the presence of other species, such as Bromus spp., Eruca vesicaria (roquette), Stipa capensis, and Medicago spp. The ewe diet consisted of natural pastures, if necessary, and some supplementation of 150 to $250 \mathrm{~g} /$ day based on barley and lucerne hay in drought, hunger season (autumn season), and in some physiological stages, such as at the time of preparation for breeding (flushing) and for lambing (steaming). Four weeks before parturition, the ewes received barley-based supplements to prevent abortions, as well as to improve milk production and quality. Fifteen days after lambing, the lambs were vaccinated against enterotoxemia. During the first two months, the lambs of two season remained in the sheepfold during the day; they were given a supplement based on lucerne hay and barley ad libitum. Then, in the third month, the lambs were pastured in extensive areas of the rural commune of Ain Beni-Mathar (-2.0247 longitude, 34.0081 latitude, and $921 \mathrm{~m}$ altitude), with supplementation based on barley (230-250 g/day for SA lambs vs. 100-120 g/day for WS lambs) and lucerne hay. Before slaughter, the lambs underwent a 45-day finishing phase based on barley (1 to $1.5 \mathrm{~kg} /$ day) and lucerne hay. The lambs had free access to water and mineral-vitamin supplement, in the form of a lick block. The difference between the two seasons is the share of pasture and concentrate supplementary foods (barely) in the feed ration of lambs and their mothers, where the maximum of pasture and the minimum of barley-based supplement are in the spring conversely in winter. No information was available on the diet chemical composition that they received. The breeders of these lambs are members of the National Association for Sheep and Goat Breeders, and they adopt a rhythm of one lambing per year and practice a pastoral farming system.

In each season, ten female lambs were slaughtered after 12 hours fasting (under water diet) at a local slaughterhouse and the slaughter procedure was carried out according to the Halal procedure. After animals slaughter, the carcasses were kept in the chilling chamber at $4^{\circ} \mathrm{C}$ for 24 hours. The meat analyses and chemical analyses were carried out on LL muscle obtained $24 \mathrm{~h}$ after slaughter.

2.2. $\mathrm{pH}$ Measurements. The $\mathrm{pH}$ was measured $24 \mathrm{~h}$ postmortem in twenty LL muscles (obtained from ten female lambs in each season) using a $\mathrm{pH}$ meter with Penetration Probe (pH/Cond 340i WTW, Weilheim, Germany).

2.3. Meat Color. $24 \mathrm{~h}$ postmortem, the meat color was successively determined on the LL muscle, according to the CIELAB system proposed by the international center of lighting (CIE) using a Chromameter 400: Konica Minolta CR400 $\left(L^{*}=\right.$ clarity, $a^{*}=$ red-green color, $b^{*}=$ yellow-blue color). A D65 illuminant was used at an observation angle of $10^{\circ}$ and with an aperture of $30 \mathrm{~mm}$. The instrument was calibrated using white standard coordinates. Chromaticity $\left(C^{*}=\left(a^{* 2}+b^{* 2}\right)^{1 / 2}\right)$ and hue angle $\left(H^{*}=\arctan \left(b^{*} / a^{*}\right)\right)$ were calculated [8]. Color measurements were made on freshly cut surfaces and represent the mean of 3 measurements performed on the LL muscle. 
2.4. Water Holding Capacity. The water holding capacity (WHC) was estimated $24 \mathrm{~h}$ postmortem by application of a mechanical force, in accordance with the method described by Grau and Hamm [9]. The samples were sliced into $1 \mathrm{~cm}$ thick steaks, with a diameter of $4 \mathrm{~cm}^{2}$, wrapped in a layer of gauze, placed between preweighed Whatman papers. The WHC was calculated by the difference of sample weight before and after being subjected to the pressure of $2.250 \mathrm{~kg}$ for $5 \mathrm{~min}$.

$$
\text { WHC }(\%)=\left(\frac{(\text { initial weight of the meat }- \text { final weight of the meat })}{\text { initial weight of the meat }}\right) \times 100 \text {. }
$$

2.5. Chemical Analyses. Before analyses, LL muscle samples were frozen, lyophilized, crushed, and stored at $-20^{\circ} \mathrm{C}$ for subsequent analyses. Dry matter was calculated using the drying method in a stove for $100^{\circ} \mathrm{C} \pm 3^{\circ} \mathrm{C}$ according to the method described by the Association of Official Analytical Chemists [10]. Intramuscular fat (IMF) was extracted and quantified according to Bligh and Dyer [11] by using a mixture of chloroform/methanol/water mixture (2/1/1; $v / v / v)$. Ash was determined by combustion (incineration) in the oven according to AOAC [10]. The Total nitrogen was quantified using the Kjeldahl method according to AOAC [10]. Total proteins were calculated using the conversion index of 6.25 .

2.6. Fatty Acids Profile. The lipid extract was methylated before analysis. The fatty acids were converted to fatty acid methyl esters (FAME) according to the method described by Ben Moumen et al. [12] using BF3 at 14\% weight in methanol. Separation of the FAMEs was performed on an Agilent gas chromatograph (GC) (HP6890 series, Agilent Technologies, USA), equipped with an Omega wax capillary column $(30 \mathrm{~m} \times 0.25 \mathrm{~mm}, 0.25 \mathrm{~m}$ film thickness) from Supelco (Bellefonte, PA, USA) and a flame ionization detector (FID). Helium (99.999\%, Air Liquide, Liege, Belgium) was used as the carrier gas, at a flow rate of $1.7 \mathrm{ml} / \mathrm{min}$. The temperatures of the injector and detector were set at 150 and $250^{\circ} \mathrm{C}$, respectively, and the oven temperature was at $210^{\circ} \mathrm{C}$. The injection volume was $1 \mu \mathrm{L}$, in splitless mode. A FAME standard, containing 37 components (Supelco, Bellefonte, PA, USA), was used to identify the individual peaks. The average amount of each fatty acid was used to calculate the sum, ratios, and lipid indices of the meat. Saturated fatty acids (SFA) were the sum of C10:0, C12:0, C13:0, C14:0, C15:0, C16:0, C17:0, $\mathrm{C} 18: 0, \mathrm{C} 20: 0, \mathrm{C} 21: 0, \mathrm{C} 23: 0$, and C24:0. Monounsaturated fatty acids (MUFA) were the sum of C14:1, C15:1, C16:1, $\mathrm{C} 17: 1$, cis/trans-C18:1, C20:1n-9, and C24:1n9. Polyunsaturated fatty acids (PUFA) were the sum of $n-3$ (C18:3n3, $\mathrm{C} 20: 3 n 3, \mathrm{C} 20: 5 n 3$, and $\mathrm{C} 22: 6 n 3$ ) and $n-6$ (cis/trans-C18: $2 n 6$, C18:3n6, C20:3n6, and C20:4n6) fatty acids. Unsaturated fatty acids (UFA) were the sum of MUFA and PUFA. Desirable fatty acids (DFA) were C18:0 and UFA. Odd fatty acids (OFA) were the sum of $\mathrm{C} 15: 0, \mathrm{C} 17: 0, \mathrm{C} 17: 1$, and $\mathrm{C} 23$ : 0 . Thrombogenic Index $(\mathrm{TI})=(\mathrm{C} 14: 0+\mathrm{C} 16: 0) /((0.5 *$ MUFA $)+(0.5 * n-6)+(3 * n-3)+(n-3 / n-6)) \quad$ without the inclusion of $18: 0$ which is considered to be neutral on serum cholesterol. Atherogenic Index $(\mathrm{AI})=((4 * 14: 0)+16$ :
0) Tapez une équation ici./((AGPI) + (AGMI)) [13]. Hypocholesterolemic fatty acids (h) were the sum of C18:1, C18: $2 n 6, \mathrm{C} 18: 3 n 6, \mathrm{C} 20: 4 n 6, \mathrm{C} 18: 3 n 3, \mathrm{C} 20: 5 n 3, \mathrm{C} 20: 3 n 3, \mathrm{C} 20$ : $3 n 6$, and $\mathrm{C} 22: 6 n 3$. Hypercholesterolemic fatty acids $(\mathrm{H})$ were the sum of $\mathrm{C} 14: 0$ and $\mathrm{C} 16: 0$. The $h / H$ was calculated according to Fernández et al. [14].

2.7. Statistical Analyses. Experimental results were presented as means \pm standard deviation of triplicate determinations. The statistical analyses were achieved using the software SPSS version 20 and considering the rearing season (summer-autumn vs. winter-spring) as source of variation. The means were compared using the $t$-test and the significance was declared at $p<0.05$.

\section{Results and Discussion}

The effect of the slaughter season on the qualitative characteristics of Beni-Guil sheep meat is presented in Tables 1-3. The results show that the season has a significant effect on the meat qualitative and quantitative characteristics of Beni-Guil breed $(p<0.05)$.

3.1. Meat Physical Characteristics. The $\mathrm{pH}$ of meat is an extremely important commercial quality criterion for the slaughterer, the processor, and the distributor. It affects the quality characteristics of the meat, particularly juiciness and color. In the present study, the $\mathrm{pH}$ values obtained for the lambs of the two seasons varied between 5.72 and 5.79 (Table 1), which could be considered within the desired range for meat quality [15]. These values are similar to the results of other studies [15-17]. The results show that lambs slaughtered in winter have a lower $\mathrm{pH}$ value than those slaughtered in spring $(p<0.05)$. This difference can be explained by the quantity of concentrate ingested by winter lambs compared to spring, which promotes ruminal fermentation and therefore the production of propionic acid, the precursor of muscle glycogen. Our results are in agreement with those reported by Yalcintan et al. [18], where the higher $\mathrm{pH}$ values have been observed in winter compared to spring. In contrast, D'Alessandro et al. [19] reported that spring lambs have lower $\mathrm{pH}$ values than winter lambs. They explain this result by a high amount of milk suckled from their mother. The amount of milk, as well as the lactose content, has been positively linked to the production of muscle glycogen [20]. 
TABLE 1: Rearing season effect on the meat quality characteristics of Beni-Guil sheep breed.

\begin{tabular}{|c|c|c|c|c|}
\hline \multirow{2}{*}{ Parameters } & \multirow{2}{*}{ Mean } & \multicolumn{2}{|c|}{ Rearing season } & \multirow{2}{*}{ Significance } \\
\hline & & Summer-autumn & Winter-spring & \\
\hline $\mathrm{pH}$ & $5.76 \pm 0.17$ & $5.72 \pm 0.2$ & $5.79 \pm 0.14$ & $* *$ \\
\hline WHC (\%) & $19.32 \pm 3.86$ & $15.91 \pm 1.23$ & $22.73 \pm 2.31$ & $* * *$ \\
\hline$L^{*}$ (lightness) & $44.03 \pm 4.14$ & $47.03 \pm 1.31$ & $41.04 \pm 4.67$ & $* *$ \\
\hline$a^{*}$ (redness) & $14.65 \pm 4.96$ & $12.62 \pm 0.96$ & $16.68 \pm 5.93$ & $* *$ \\
\hline$b^{*}$ (yellowness) & $15.27 \pm 4.17$ & $13.43 \pm 0.79$ & $17.12 \pm 4.91$ & $* *$ \\
\hline$C^{*}$ (chromaticity) & $21.21 \pm 6.3$ & $18.46 \pm 0.75$ & $23.97 \pm 7.47$ & $* *$ \\
\hline Hue angle $\left({ }^{\circ}\right)$ & $46.63 \pm 3.99$ & $46.80 \pm 3.14$ & $46.47 \pm 4.58$ & NS \\
\hline$a^{*} / b^{*}$ & $0.95 \pm 0.13$ & $0.94 \pm 0.1$ & $0.96 \pm 0.15$ & NS \\
\hline $\operatorname{IMF}(\%)$ & $4.48 \pm 1.33$ & $3.82 \pm 1.72$ & $5.14 \pm 0.65$ & $*$ \\
\hline Ash (\%) & $0.98 \pm 0.09$ & $1.02 \pm 0.06$ & $0.94 \pm 0.1$ & $*$ \\
\hline Proteins (\%) & $20.42 \pm 1.29$ & $21.41 \pm 0.56$ & $19.43 \pm 1$ & $* * *$ \\
\hline Dry matter (\%) & $25.72 \pm 1.46$ & $25.71 \pm 1.99$ & $25.72 \pm 1.1$ & NS \\
\hline
\end{tabular}

${ }^{*} p<0.05 ;{ }^{* *} p<0.01 ;{ }^{* * *} p<0.001$; IMF: intramuscular fat; WHC: water holding capacity.

TABLE 2: Rearing season effect on the fatty acids profile of Beni-Guil sheep breed.

\begin{tabular}{|c|c|c|c|c|}
\hline \multirow{2}{*}{ Fatty acids (\%) } & \multirow{2}{*}{ Mean } & \multicolumn{2}{|c|}{ Rearing season } & \multirow{2}{*}{ Significance } \\
\hline & & Summer-autumn & Winter-spring & \\
\hline C10:0 & $0.16 \pm 0.07$ & $0.12 \pm 0.05$ & $0.20 \pm 0.07$ & $* *$ \\
\hline C12:0 & $0.24 \pm 0.1$ & $0.15 \pm 0.06$ & $0.34 \pm 0.18$ & $* * *$ \\
\hline $\mathrm{C} 13: 0$ & $0.03 \pm 0.01$ & $0.02 \pm 0.00$ & $0.03 \pm 0.01$ & $*$ \\
\hline C14:0 & $3.05 \pm 1.70$ & $1.87 \pm 0.31$ & $4.24 \pm 1.65$ & $* * *$ \\
\hline $\mathrm{C} 14: 1$ & $0.18 \pm 0.04$ & $0.22 \pm 0.02$ & $0.14 \pm 0.06$ & NS \\
\hline $\mathrm{C} 15: 0$ & $0.48 \pm 0.07$ & $0.40 \pm 0.11$ & $0.57 \pm 0.07$ & $* * *$ \\
\hline $\mathrm{C} 15: 1$ & $0.13 \pm 0.07$ & $0.15 \pm 0.07$ & $0.12 \pm 0.08$ & NS \\
\hline $\mathrm{C} 16: 0$ & $22.6 \pm 2.5$ & $20.47 \pm 1.50$ & $24.73 \pm 1.45$ & $* * *$ \\
\hline $\mathrm{C} 16: \ln 7$ & $0.36 \pm 0.04$ & $0.35 \pm 0.04$ & $0.38 \pm 0.04$ & NS \\
\hline $\mathrm{C} 16: \ln 9$ & $1.80 \pm 0.36$ & $1.97 \pm 0.36$ & $1.63 \pm 0.30$ & $* *$ \\
\hline $\mathrm{C} 17: 0$ & $1.42 \pm 0.40$ & $1.50 \pm 0.62$ & $1.34 \pm 0.09$ & NS \\
\hline $\mathrm{C} 17: 1$ & $0.95 \pm 0.24$ & $1.09 \pm 0.28$ & $0.81 \pm 0.11$ & $* * *$ \\
\hline $\mathrm{C} 18: 0$ & $16.08 \pm 2.76$ & $15.15 \pm 0.89$ & $17.02 \pm 3.36$ & $*$ \\
\hline Cis/trans-C18: $\ln 9$ & $36.79 \pm 3.64$ & $38.26 \pm 3.43$ & $35.33 \pm 3.35$ & $*$ \\
\hline Cis/trans-C18:2n6 & $8.15 \pm 2.23$ & $9.33 \pm 2.82$ & $6.98 \pm 0.82$ & $* *$ \\
\hline $\mathrm{C} 18: 3 n 6$ & $0.81 \pm 0.30$ & $0.74 \pm 0.07$ & $0.89 \pm 0.04$ & NS \\
\hline $\mathrm{C} 18: 3 n 3$ & $1.52 \pm 1.04$ & $0.51 \pm 0.10$ & $2.54 \pm 0.33$ & $* * *$ \\
\hline $\mathrm{C} 20: 0$ & $0.10 \pm 0.05$ & ND & $0.10 \pm 0.05$ & $* * *$ \\
\hline $\mathrm{C} 20: \ln 9$ & $0.12 \pm 0.04$ & $0.18 \pm 0.03$ & $0.07 \pm 0.01$ & $*$ \\
\hline $\mathrm{C} 20: 2$ & $0.4 \pm 0.2$ & $0.60 \pm 0.20$ & $0.20 \pm 0.1$ & $* * *$ \\
\hline $\mathrm{C} 20: 3 n 6$ & $0.30 \pm 0.18$ & $0.39 \pm 0.10$ & $0.22 \pm 0.02$ & $*$ \\
\hline $\mathrm{C} 20: 3 n 3$ & $0.09 \pm 0.08$ & $0.09 \pm 0.02$ & ND & $* * *$ \\
\hline $\mathrm{C} 20: 4 n 6$ & $2.98 \pm 1.3$ & $4.42 \pm 1.36$ & $1.54 \pm 0.02$ & $* * *$ \\
\hline $\mathrm{C} 20: 5 n 3$ & $0.23 \pm 0.10$ & $0.43 \pm 0.02$ & $0.04 \pm 0.01$ & $* * *$ \\
\hline $\mathrm{C} 21: 0$ & $0.65 \pm 0.27$ & ND & $0.65 \pm 0.27$ & $* * *$ \\
\hline $\mathrm{C} 22: 2$ & $0.11 \pm 0.09$ & $0.11 \pm 0.09$ & ND & $* * *$ \\
\hline $\mathrm{C} 23: 0$ & $0.28 \pm 0.10$ & $0.28 \pm 0.1$ & ND & $* * *$ \\
\hline $\mathrm{C} 24: 0$ & $0.49 \pm 0.20$ & $0.76 \pm 0.05$ & $0.23 \pm 0.08$ & $* * *$ \\
\hline $\mathrm{C} 22: 6 n 3$ & $0.21 \pm 0.02$ & $0.21 \pm 0.02$ & ND & $* * *$ \\
\hline $\mathrm{C} 24: \ln 9$ & $0.25 \pm 0.02$ & $0.25 \pm 0.02$ & ND & $* * *$ \\
\hline
\end{tabular}

NS: not significant; ND: not detected; ${ }^{*} p<0.05 ;{ }^{* *} p<0.01 ;{ }^{* * *} p<0.001$.

The water holding capacity was determined using analyses of the expressed juiciness. The results show that spring lamb meat has a lower water retention capacity, because it lost more water than winter lamb meat. Likewise, several authors who have studied the effect of the season and the production system have reported that meat raised in spring has a lower water retention capacity $[18,21,22]$. On one hand, this result can be explained by the difference recorded in $\mathrm{pH}$ between the seasons (Table 1). Meats with a $\mathrm{pH}$ close to the proteins isoelectric point tend to be drier. We get closer to the isoelectric point of meat proteins. Their charges decrease and they tighten by a reciprocal attraction effect. 
TABle 3: Rearing season effect on the sums, ratios, and indices of fatty acids profile of Beni-Guil sheep breed.

\begin{tabular}{|c|c|c|c|c|}
\hline \multirow{2}{*}{ Sums, ratios, and indices of FA } & \multirow{2}{*}{ Mean } & \multicolumn{2}{|c|}{ Rearing season } & \multirow{2}{*}{ Significance } \\
\hline & & Summer-autumn & Winter-spring & \\
\hline SFA & $45.09 \pm 5.09$ & $40.73 \pm 2.33$ & $49.45 \pm 2.88$ & $* * *$ \\
\hline MUFA & $40.46 \pm 4.13$ & $42.44 \pm 4.02$ & $38.48 \pm 3.43$ & $* *$ \\
\hline PUFA & $14.61 \pm 4.52$ & $16.82 \pm 5.98$ & $12.40 \pm 1.51$ & $* *$ \\
\hline UFA & $55.07 \pm 5.09$ & $59.26 \pm 2.33$ & $50.88 \pm 3.29$ & $* * *$ \\
\hline DFA & $71.15 \pm 4.22$ & $74.41 \pm 1.5$ & $67.90 \pm 3.32$ & $* * *$ \\
\hline OFA & $3.33 \pm 0.73$ & $3.14 \pm 1.01$ & $3.52 \pm 0.41$ & NS \\
\hline UFA/SFA & $1.25 \pm 0.25$ & $1.46 \pm 0.14$ & $1.04 \pm 0.12$ & $* * *$ \\
\hline PUFA/SFA & $0.33 \pm 0.13$ & $0.42 \pm 0.16$ & $0.25 \pm 0.03$ & $* *$ \\
\hline PUFA $n-6$ & $12.25 \pm 2.28$ & $14.88 \pm 4.36$ & $9.62 \pm 1.29$ & $* *$ \\
\hline PUFA $n-3$ & $1.86 \pm 0.79$ & $1.14 \pm 0.36$ & $2.58 \pm 0.33$ & $* * *$ \\
\hline$n-6 / n-3$ & $8.38 \pm 2.94$ & $12.98 \pm 2.26$ & $3.78 \pm 0.61$ & $* * *$ \\
\hline TI & $0.81 \pm 0.16$ & $0.70 \pm 0.10$ & $0.91 \pm 0.15$ & $* * *$ \\
\hline AI & $0.65 \pm 0.22$ & $0.47 \pm 0.05$ & $0.83 \pm 0.17$ & $* * *$ \\
\hline $\mathrm{h} / \mathrm{H}$ & $2.08 \pm 0.48$ & $2.5 \pm 0.31$ & $1.67 \pm 0.22$ & $* * *$ \\
\hline NVF & $2.37 \pm 0.31$ & $2.61 \pm 0.28$ & $2.13 \pm 0.25$ & $* * *$ \\
\hline
\end{tabular}

${ }^{*} p<0.05 ;{ }^{* *} p<0.01 ;{ }^{* * *} p<0.001$; NS: not significant; ND: nondetected; SFA: saturated fatty acids; UFA: unsaturated fatty acids; PUFA: polyunsaturated fatty acids; DFA: desirable fatty acids; (C18: $0+$ UFA); OFA: odd fatty acids; TI $=$ thrombogenic index: $(\mathrm{C} 14: 0+\mathrm{C} 16: 0) /\left((0.5 *\right.$ MUFA $)+\left(0.5 * \sum \mathrm{n}-6\right)+$ $\left.\left(3 * \sum \mathrm{n}-3\right)+(\mathrm{n}-3 / \mathrm{n}-6)\right) . \mathrm{AI}=$ atherogenic index: $((4 * \mathrm{C} 14: 0)+\mathrm{C} 16: 0) /((\mathrm{PUFA})+(\mathrm{MUFA}))$, according to Ulbricht and Southgate [33] without the inclusion of $18: 0$ which is considered to be neutral on serum cholesterol; hypocholesterolemic $(h) /$ hypercholesterolemic $(H)=(18: 1 n 9 \mathrm{c}+18: 2 \omega 6+20$ : $4 \omega 6+18: 3 n 3+20: 5 n 3+22: 6 n 3) /(14: 0+16: 0)$; fat nutritive value (NVF): $(\mathrm{C} 18: 0+\mathrm{C} 18: 1) / \mathrm{C} 16: 0$.

These changes decrease the muscle's water retention capacity, therefore loss of mass during storage. On the other hand, this result can be explained by the water richness of the spring food ration, and consequently, a juicy meat rich in intramuscular juice.

Meat color is not an important dietary characteristic, but it is a decisive factor in the initial choice of meat by consumers [20]. In the Mediterranean countries, consumers prefer mainly sheep meat with a bright red or pink color, as it is also the case in the Middle East $[18,23]$. The results show that all the meat has a bright red color with luminance values $\left(L^{*}\right)$ between 41.04 and 47.03. Several studies have shown that meat from grazing lambs is darker than that from underconcentrated lambs due to physical activity, which increase the amount of hemoglobin (pigment) and by the final meat's $\mathrm{pH}[24,25]$. On one hand, the recorded difference in lightness is mainly due to recorded $\mathrm{pH}$ values and intramuscular fat content. Then we get close to the isoelectric $\mathrm{pH}$ of the actin and myosin proteins, allowing the neutralization of the charges and reduction in the spacing of the muscle fibers. This muscular protein network then presents a "closed" structure. These changes affect how light is reflected and absorbed and reduce light penetration into the muscle, giving the meat a bright red appearance [25]. On the other hand, Hanekom [25] reports that the three muscles from extensively reared lambs contained significantly more myoglobin than those from lambs raised intensively. Numerous researchers concluded that lambs reared extensively produce darker meat due to high levels of activity associated with the production system $[26,27]$. In agreement to previous studies, spring lambs have a significantly darker color than winter ones $(p<0.05)$. Since we used lambs of the same age and weight at slaughter, in fact, this result can be explained by the $\mathrm{pH}$ value and by the distance covered by spring lambs, since they were reared outdoor with their mothers from the third month of age. On the other hand, those slaughtered in winter, when unfavorable climatic conditions occur, remain indoor because there is practically no pasture persistence to graze outdoor.

Regarding the intramuscular (IMF) fat content, the results show that the season has a significant effect $(p<0.05)$. Lambs from WS presented higher IMF compared to SA group ( $5.14 \%$ vs. $3.82 \%$, respectively). This effect can be attributed to the grazing-based farming system, which generally results in better milk production characterized by a high-fat content due to a diet rich in fiber [28]. Lambs slaughtered in the spring have the highest ash content $(p<0.05)$. This can be attributed to the availability of pasture in spring. Cabrera and Saadoun [29] reported that meats from pasture are richer in minerals than those on a concentrate diet.

3.2. Fatty Acids Profile Analysis. Tables 2 and 3 present the effect of rearing season on intramuscular fat from LL muscle (percentage of fatty acids by total weight of fatty acids, their sums. and their indices) of Beni-Guil sheep. The results show that the fatty acid profile of SA lambs was significantly different from those of WS season $(p<0.05)$. The chromatograms obtained from the FAME analysis by GC-FID revealed the presence of 25 and 28 fatty acids in the intramuscular fat of the LL muscle of WS and SA lambs, respectively (Table 2 ). In general, the obtained profiles were similar to those reported for Beni-Guil sheep breed [30, 31]. The sums, ratios, and indices of FAs are presented in Table 3. The fraction of saturated fatty acids (SFA) is often considered to be detrimental to our health [32]. However, recent studies have pointed to the gap between scientific literature and commonly accepted dietary recommendations [32]. Among the SFA identified in the analyzed meats, those with 
short and medium chain (C10:0; C12:0; C14:0; C16:0) constitute the majority, with a dominance of $\mathrm{C} 16: 0$ which is often considered as an undesirable cholesterol factor [33]. However, long-chain (C18:0) and short-chain SFA are considered as FA with a neutral effect on bad cholesterol and are capable of increasing the content of good cholesterol $[34,35]$. The results show that the meat of the WS lambs is rich in medium- and long-chain fatty acids (C12:0; C14:0; C16:0; C18:0). Similar results were reported by other authors on sheep meat $[17,36]$. Also, Velasco et al. [36] reported that the fatty acid composition of lamb meat is closely related to the fatty acid composition of their mothers' milk, which is rich in medium-chain and saturated fatty acids. This difference may be due to the difference in milk production performance between the two studied seasons. In particular, WS lambs practically receive more milk than those born in the dry season (SA season). Moreover, in a previous study, Beriain et al. [37] reported that the milk diet produces high levels of $\mathrm{C} 14: 0$ and $\mathrm{C} 16: 0$, while pastures produce high levels of $\mathrm{C} 18: 0$ fatty acids.

Concerning monounsaturated fatty acids, the highest percentage is found in the meat of SA lambs $(42.44 \%$ vs. $38.48 \% ; p<0.05)$. This difference is mainly due to the difference in oleic acid $(\mathrm{C} 18: 1)$, which dominates this fraction with a percentage of more than $90 \%$ and which is considered as fatty acid with hypocholesterolemic property $[34,38]$. This result can be attributed to the breeding system adopted in the autumn-winter season, which is mainly based on a ration rich in concentrate because of the scarcity of grazing in this season. Scerra et al. [39] found that meat from a stalling system has a higher oleic acid content than that produced on pasture. In addition, the meat of SA lambs has the highest content of polyunsaturated fatty acid (16.82\% vs. $12.4 \% ; p<0.05)$. This finding can be explained by the diet in the autumn-winter season which is rich in concentrate (rich in carbohydrates), influencing the time of feed congestion in rumen, decreasing the biohydrogenation of unsaturated fatty acids [40]. Thus, Sauvant and Bas [40] have reported that the food intake rich in carbohydrates affects the residence time of lipids in the rumen and, consequently, decreases their biohydrogenation. In addition, the higher $\mathrm{C} 18$ : $2 n 6$ content in the meat of SA lambs may arise, likely, from a high content of this FA in the concentrate [41, 42]. The PUFA $n-6 /$ PUFA $n-3$ ratio is an important parameter to evaluate the nutritional quality of meat fat in regard to the prevention of coronary heart diseases and anticarcinogenic activity, in the context of human health, which is recommended to be below $4[29,43]$. Meanwhile, PUFA/SFA is recommended to be above 0.4 . The results show that the rearing season influenced the ratios, nutritional indices, and nutritional value of the intramuscular fat $(n-6 / n-3, \mathrm{AI}, \mathrm{h} /$ $\mathrm{H})$. In particular, the proportion of linoleic $(\mathrm{C} 18: 2)$ and arachidonic (C20:4n6) acids was significantly higher $(p<0.05)$ in the muscle of the SA lambs. This higher content in C18:2n6 and its metabolites in the meat of lambs reared in autumn-winter may arise, likely, from a high content of this FA in the concentrate $[22,26]$. This is associated, from one side, with more favorable ratios of PUFA/AGS ( 0.42 vs. 0.25) above the recommended value (0.4) [44], hypocholesterolemic/hypercholesterolemic (2.5 vs. 1.67), and an interesting nutritional value (2.61 vs. 2.13$)$, while from another side, it is associated with an unfavorable $n-6 /$ $n-3$ ratio (12.98). The SA lambs have a higher $n-6 / n-3$ ratio (12.98) compared to the nutritional recommendations. This richness could be explained by the use of barley (Hordeum vulgare) as a main concentrate supplement food in the dry season which is rich in PUFA $n-6$ [45]. Yousefi et al. [46] report lower PUFA/SFA ratios for lambs of two Iranian breeds $(0.19$ and 0.16$)$ to ours. Similar to findings from this study for SA lambs, Sinanoglou et al. [47] reported PUFA/SFA ratios between 0.37 and 0.49 for Greek lambs. However, WS lambs have a high content of linolenic acid $(0.5 \%$ vs. $2.54 \%)$ and a favorable $n-6 / n-3(3.78)$ ratio. The SA lambs have a higher $n-6 / n-3$ ratio (12.98) compared to the nutritional recommendations, considering the fact that this ratio intake by humans should not exceed the value of 4 [43]. This result is due to the pasture availability in WS season, which is associated with the increase in the proportion of linolenic acid (ALA). Pasture is linked to a higher PUFA $n-3$ content since the grasses chloroplasts may provide a natural protection of PUFA in the rumen compared to concentrate-based diet [48]. Valvo et al. [49] and Atti et al. [50] reported that sheep raised on pasture produce ALA-rich milk compared to those fed in a stable. Indeed, Velasco et al. [51] reported that pasture-fed suckling lambs produce meats richer in PUFA and lower in $n-6 / n-3$ ratios compared to the profile of suckling lambs raised on a highconcentrate ration. Interestingly, Scerra et al. [39] found that the proportion of PUFA was higher in muscular fat of lambs whose mothers had access to pasture than lambs from ewes of a stall-fed group. The obtained $n-6 / n-3$ ratio for WS lambs is lower than those reported by Berrighi et al. [52] for Reimbi sheep breed, by Vasta et al. [53] for Barbarine sheep breed and Blasco et al. [54] for Segureña lambs (15.32-15.47). However, the recorded values are higher than those reported by Margetín et al. [55] for Ile de France breed (1.86-2.23). The nutritional indices (AI and TI) represent key parameters to assess the effect of proatherogenics on the potential risk of blood platelets aggregation [47, 56]. According to Sinanoglou et al. [47], AI and TI should not exceed 1.0. In this context, our results show that the lambs presented favorable AI and TI values which do not exceed the norm, with the superiority of the SA lambs (AI: 0,47 vs. $0,83<1$; TI: 0.70 vs. $0.91<1$ ). This recorded value is similar to the results reported by Sinanoglou et al. [47] for Lacaune (0.83) and Chios (0.91) lambs and is lower than those found by Margetín et al. [55] in sheep meat of the Ile de France breed raised on pasture and by Vacca et al. [56] in the meat of the Sarda breed and its crosses.

\section{Conclusion}

The effect of the season on the quality of intramuscular lipids has been studied. The results show that the rearing or slaughtering season has a significant effect on the physicochemical characteristics of Beni-Guil sheep meat. In particular, the meat of female lambs raised in the winterspring season had a higher content of intramuscular fat and 
polyunsaturated fatty acid with favorable $n-6 / n-3$ ratio. On the other hand, those reared in autumn-winter season have high content of PUFA and more favorable PUFA/SFA ratio.

\section{Data Availability}

The data used to support the findings of this study are available from the corresponding author upon request.

\section{Conflicts of Interest}

The authors declare that they have no conflicts of interest.

\section{Authors' Contributions}

$\mathrm{KB}$ was responsible for designing the research methodology, carried out all experimental tasks, and wrote the first draft of the manuscript; FM was responsible for statistical analysis and data interpretation; MS and MB carried out data analysis and interpretation; MLF contributed to designing the research methodology and data analysis; $\mathrm{SCH}$ and $\mathrm{AE}$ conceived the study, contributed to the design and coordination, supervised all analyses, and finished the final version of the manuscript.

\section{Acknowledgments}

The authors acknowledge the Wallonie-Bruxelles International (WBI) for funding this research in the context of Program of Scientific Cooperation between Morocco and Wallonia Brussels, for the years 2015-2018, under grant agreement number project 1-6.

\section{References}

[1] J. Li and Q. Sun, "Consumption of saturated fatty acids and coronary heart disease risk," International Journal of Cardiology, vol. 279, pp. 27-28, 2019.

[2] P. Vahmani, E. N. Ponnampalam, J. Kraft et al., "Bioactivity and health effects of ruminant meat lipids. Invited Review," Meat Science, vol. 165, pp. 108-114, 2020.

[3] M. Dehghan, A. Mente, X. Zhang et al., "Associations of fats and carbohydrate intake with cardiovascular disease and mortality in 18 countries from five continents (PURE): a prospective cohort study," The Lancet, vol. 390, no. 10107, pp. 2050-2062, 2017.

[4] F. Visioli and A. Poli, "Fatty acids and cardiovascular risk. Evidence, lack of evidence, and diligence," Nutrients, vol. 12, no. 12 , p. $3782,2020$.

[5] P. Howe, J. Buckley, and B. Meyer, "Long-chain omega-3 fatty acids in red meat," Nutrition \& Dietetics: The Journal of the Dietitians Association of Australia, vol. 64, no. 3, p. S135, 2007.

[6] L. Sagot and E. Pottier, "La grille EUROP de classement pour l'état d'engraissement," 2011, http://idele.fr/filieres/bovin-lait/ publication/idelesolr/recommends/la-grille-europ-de-classementpour-letat-dengraissement.html.

[7] L. Sagot and E. Pottier, "La grille de classement pour la conformation," 2011, http://idele.fr/filieres/bovin-lait/publication/ idelesolr/recommends/la-grille-europ-de-classement-pour-laconformation.html.
[8] H. Calnan, R. H. Jacob, D. W. Pethick, and G. E. Gardner, "Production factors influence fresh lamb longissimus colour more than muscle traits such as myoglobin concentration and pH," Meat Science, vol. 119, pp. 41-50, 2016.

[9] R. Grau and R. Hamm, "Eine einfache methode zur bestimmung der wasserbindung im muskel," Die Naturwissenschaften, vol. 40, no. 1, pp. 29-30, 1953.

[10] AOAC, Official Methods of Analysis of the Association of Official Analytical Chemists, Association of Official Analytical Chemists, Washington, DC, USA, 15th edition, 1990.

[11] E. G. Bligh and W. J. Dyer, "A rapid method of total lipid extraction and purification," Canadian Journal of Biochemistry and Physiology, vol. 37, no. 8, pp. 911-917, 1959.

[12] A. Ben Moumen, F. Mansouri, G. Richard et al., "Biochemical characterisation of the seed oils of four safflower (Carthamus tinctorius) varieties grown in north-eastern of Morocco," International Journal of Food Science \& Technology, vol. 50, no. 3, pp. 804-810, 2015.

[13] L. T. Gama, M. C. Bressan, E. C. Rodrigues et al., "Heterosis for meat quality and fatty acid profiles in crosses among Bos indicus and Bos taurus finished on pasture or grain," Meat Science, vol. 93, no. 1, pp. 98-104, 2013.

[14] M. Fernández, J. A. Ordóñez, I. Cambero, C. Santos, C. Pin, and L. d. l. Hoz, "Fatty acid compositions of selected varieties of Spanish dry ham related to their nutritional implications," Food Chemistry, vol. 101, no. 1, pp. 107-112, 2007.

[15] J. F. Tejeda, R. E. Peña, and A. I. Andrés, "Effect of live weight and sex on physico-chemical and sensorial characteristics of Merino lamb meat," Meat Science, vol. 80, no. 4, pp. 1061-1067, 2008.

[16] A. Teixeira, S. Batista, R. Delfa, and V. Cadavez, "Lamb meat quality of two breeds with protected origin designation. Influence of breed, sex and live weight," Meat Science, vol. 71, no. 3, pp. 530-536, 2005.

[17] G. Mazzone, M. Giammarco, G. Vignola, L. Sardi, and L. Lambertini, "Effects of the rearing season on carcass and meat quality of suckling Apennine light lambs," Meat Science, vol. 86, no. 2, pp. 474-478, 2010.

[18] H. Yalcintan, B. Ekiz, O. Kocak, N. Dogan, P. D. Akin, and A. Yilmaz, "Carcass and meat quality characteristics of lambs reared in different seasons," Archives Animal Breeding, vol. 60, no. 3, pp. 225-233, 2017.

[19] A. G. D’Alessandro, G. Maiorano, M. Ragni, D. Casamassima, G. Marsico, and G. Martemucci, "Effects of age and season of slaughter on meat production of light lambs: carcass characteristics and meat quality of Leccese breed," Small Ruminant Research, vol. 114, no. 1, pp. 97-104, 2013.

[20] M. J. Beriain, A. Horcada, A. Purroy, G. Lizaso, J. Chasco, and J. A. Mendizabal, "Characteristics of Lacha and Rasa Aragonesa lambs slaughtered at three live weights," Journal of Animal Science, vol. 78, no. 12, pp. 3070-3077, 2000.

[21] J. Santos-Silva, I. Mendes, and R. Bessa, "The effect of genotype, feeding system and slaughter weight on the quality of light lambs: 1. Growth, carcass composition and meat quality," Livestock Production Science, vol. 76, no. 1-2, pp. 17-25, 2002.

[22] V. Cañeque, S. Velasco, F. R. Maria Teresa díaz, C. Felipe Ruiz De Huidobro, C. Pérez, and S. Lauzurica, "Use of whole barley with a protein supplement to fatten lambs under different management systems and its effect on meat and carcass quality," Animal Research, vol. 52, no. 3, pp. 271-285, 2003.

[23] B. Ekiz, A. Yilmaz, M. Ozcan, and O. Kocak, "Effect of production system on carcass measurements and meat quality of Kivircik lambs," Meat Science, vol. 90, no. 2, pp. 465-471, 2012. 
[24] S. Martínez-Cerezo, C. Sañudo, B. Panea et al., "Breed, slaughter weight and ageing time effects on physico-chemical characteristics of lamb meat," Meat Science, vol. 69, no. 2, pp. 325-333, 2005.

[25] Y. Hanekom, The Effect of Extensive and Intensive Production Systems on the Meat Quality and Carcass Characteristics of Dohne Merino Lambs, University of Stellenbosch, Stellenbosch, South Africa, 2010.

[26] M. Diaz, S. Velasco, V. Caneque et al., "Use of concentrate or pasture for fattening lambs and its effect on carcass and meat quality," Small Ruminant Research, vol. 43, no. 3, pp. 257-268, 2002.

[27] A. Priolo, D. Micol, J. Agabriel, S. Prache, and E. Dransfield, "Effect of grass or concentrate feeding systems on lamb carcass and meat quality," Meat Science, vol. 62, no. 2, pp. 179-185, 2002.

[28] P. Morand-Fehr, V. Fedele, M. Decandia, and Y. Le Frileux, "Influence of farming and feeding systems on composition and quality of goat and sheep milk," Small Ruminant Research, vol. 68, no. 1-2, pp. 20-34, 2007.

[29] M. C. Cabrera and A. Saadoun, "An overview of the nutritional value of beef and lamb meat from South America," Meat Science, vol. 98, no. 3, pp. 435-444, 2014.

[30] K. Belhaj, F. Mansouri, A. Benmoumen et al., "Fatty acids, health lipid indices, and cholesterol content of sheep meat of three breeds from Moroccan pastures," Archives Animal Breeding, vol. 63, no. 2, pp. 471-482, 2020.

[31] K. Belhaj, F. Mansouri, M. Sindic et al., "Effect of the concentrate-based finishing on the proximate composition, organoleptic quality and fatty acids profile of the Beni-Guil sheep meat," E3S Web of Conferences, vol. 183, Article ID 04001, 2020.

[32] R. Hoenselaar, "Saturated fat and cardiovascular disease: the discrepancy between the scientific literature and dietary advice," Nutrition, vol. 28, no. 2, pp. 118-123, 2012.

[33] T. L. V. Ulbricht and D. A. T. Southgate, "Coronary heart disease: seven dietary factors," The Lancet, vol. 338, no. 8773, pp. 985-992, 1991.

[34] J. M. Dietschy, "Dietary fatty acids and the regulation of plasma low density lipoprotein cholesterol concentrations," The Journal of Nutrition, vol. 128, no. 2, pp. 444S-448S, 1998.

[35] A. Bonanome and S. M. Grundy, "Effect of dietary stearic acid on plasma cholesterol and lipoprotein levels," New England Journal of Medicine, vol. 318, no. 19, pp. 1244-1248, 1988.

[36] S. Velasco, V. Cañeque, S. Lauzurica, C. Pérez, and F. Huidobro, "Effect of different feeds on meat quality and fatty acid composition of lambs fattened at pasture," Meat Science, vol. 66, no. 2, pp. 457-465, 2004.

[37] M. Beriain, P. Bas, A. Purroy, T. Treacher, I. Ledin, and P. Morand-Fehr, "Effect of animal and nutritional factors and nutrition on lamb meat quality," in Sheep and Goat Nutrition: Intake, Digestion, Quality of Products and Rangelands, P. Morand-Fehr, Ed., pp. 75-86, Cahiers Options Méditerranéennes (CIHEAM), Zaragoza, Spain, 2020.

[38] W. C. Willett, "Dietary fats and coronary heart disease," Journal of Internal Medicine, vol. 272, no. 1, pp. 13-24, 2012.

[39] M. Scerra, P. Caparra, F. Foti, V. Galofaro, M. C. Sinatra, and V. Scerra, "Influence of Ewe feeding systems on fatty acid composition of suckling lambs," Meat Science, vol. 76, no. 3, pp. 390-394, 2007.
[40] D. Sauvant and P. Bas, "La digestion des lipides chez le ruminant," Productions Animales, vol. 5, no. 14, pp. 303-310, 2001.

[41] D. Dannenberger, K. Nuernberg, G. Nuernberg, and K. Ender, "Carcass- and meat quality of pasture vs concentrate fed German Simmental and German Holstein bulls," Archives Animal Breeding, vol. 49, no. 4, pp. 315-328, 2006.

[42] K. Nuernberg, A. Fischer, G. Nuernberg, K. Ender, and D. Dannenberger, "Meat quality and fatty acid composition of lipids in muscle and fatty tissue of Skudde lambs fed grass versus concentrate," Small Ruminant Research, vol. 74, no. 1-3, pp. 279-283, 2008.

[43] N. L. Howes, A. E.-D. A. Bekhit, D. J. Burritt, and A. W. Campbell, "Opportunities and implications of pasturebased lamb fattening to enhance the long-chain fatty acid composition in meat," Comprehensive Reviews in Food Science and Food Safety, vol. 14, no. 1, pp. 22-36, 2015.

[44] J. D. Wood, R. I. Richardson, G. R. Nute et al., "Effects of fatty acids on meat quality: a review," Meat Science, vol. 66, no. 1, pp. 21-32, 2004.

[45] M. M. Özcan, F. Aljuhaimi, and N. Uslu, "Effect of malt process steps on bioactive properties and fatty acid composition of barley, green malt and malt grains," Journal of Food Science and Technology, vol. 55, no. 1, pp. 226-232, 2018.

[46] A. R. Yousefi, H. Kohram, A. Zare Shahneh, A. Nik-Khah, and A. W. Campbell, "Comparison of the meat quality and fatty acid composition of traditional fat-tailed (Chall) and tailed (Zel) Iranian sheep breeds," Meat Science, vol. 92, no. 4, pp. 417-422, 2012

[47] V. J. Sinanoglou, A. Batrinou, F. Mantis, I. Bizelis, and S. Miniadis-Meimaroglou, "Lipid quality indices: differentiation of suckling lamb and kid breeds reared by traditional sheep farming," Small Ruminant Research, vol. 113, no. 1, pp. 1-10, 2013.

[48] J. D. Wood and M. Enser, "Factors influencing fatty acids in meat and the role of antioxidants in improving meat quality," British Journal of Nutrition, vol. 78, no. 1, pp. S49-S60, 1997.

[49] M. A. Valvo, M. Lanza, M. Bella et al., "Effect of Ewe feeding system (grass v. concentrate) on intramuscular fatty acids of lambs raised exclusively on maternal milk," Animal Science, vol. 81, no. 3, pp. 431-436, 2005.

[50] N. Atti, H. Rouissi, and M. Othmane, "Milk production, milk fatty acid composition and conjugated linoleic acid (CLA) content in dairy ewes raised on feedlot or grazing pasture," Livestock Science, vol. 104, no. 1-2, pp. 121-127, 2006.

[51] S. Velasco, V. Cañeque, C. Pérez et al., "Fatty acid composition of adipose depots of suckling lambs raised under different production systems," Meat Science, vol. 59, no. 3, pp. 325-333, 2001.

[52] N. Berrighi, L. Belkacemi, K. Bouderoua, M. Santaella, G. Ros, and G. Nieto, "Fatty acids composition and sensory properties of lamb meat fed on steppe and highland pastures," Asian Journal of Animal Sciences, vol. 11, no. 2, pp. 88-95, 2017.

[53] V. Vasta, D. Aouadi, D. M. R. Brogna et al., "Effect of the dietary supplementation of essential oils from rosemary and artemisia on muscle fatty acids and volatile compound profiles in Barbarine lambs," Meat Science, vol. 95, no. 2, pp. 235-241, 2013.

[54] M. Blasco, M. M. Campo, J. Balado, and C. Sañudo, "Effect of Texel crossbreeding on productive traits, carcass and meat 
quality of Segureña lambs," Journal of the Science of Food and Agriculture, vol. 99, no. 7, pp. 3335-3342, 2019.

[55] M. Margetín, M. Oravcová, J. Margetínová, and R. Kubinec, "Fatty acids in intramuscular fat of Ile de France lambs in two different production systems," Archives Animal Breeding, vol. 61, no. 4, pp. 395-403, 2018.

[56] G. M. Vacca, V. Carcangiu, M. L. Dettori et al., "Productive performance and meat quality of Mouflon $\times$ Sarda and Sarda $\times$ Sarda suckling lambs," Meat Science, vol. 80, no. 2, pp. 326-334, 2008. 